\title{
Effects of hydroxyl radical induced-injury in atrial versus ventricular myocardium of dog and rabbit
}

\author{
Nitisha Hiranandani, George E. Billman and Paul M. L. Janssen* \\ Department of Physiology and Cell Biology, College of Medicine, The Ohio State University, Columbus, OH, USA
}

\section{Edited by:}

David Fulton, Medical College of

Georgia, USA

Reviewed by:

R. Dan Rudic, Medical College of

Georgia, USA

Scarlet Y. Shi, Medical College of

Wisconsin, USA

Richard E. White, Medical College of

Georgia, USA

*Correspondence:

Paul M. L. Janssen, Department of Physiology and Cell Biology, The Ohio State University, 304 Hamilton Hall, 1645 Neil Avenue, Columbus, $\mathrm{OH}$ 43210-1218, USA.

e-mail: janssen.10@osu.edu
Despite the widespread use of ventricular tissue in the investigation involving hydroxyl radical Aim: $\left(\mathrm{OH}^{*}\right)$ injury, one of the most potent mediators in ischemia-reperfusion injury, little is known about the impact on atrial myocardium. In this study we thus compared the $\mathrm{OH}^{*}$-induced injury response between atrial and right ventricular muscles from both rabbits and dogs under identical experimental conditions. Methods: Small, contracting ventricular and atrial rabbit and dog trabeculae were directly exposed to $\mathrm{OH}^{*}$, and contractile properties were examined and quantified. Results: A brief $\mathrm{OH}^{*}$ exposure led to transient rigor like contracture with marked elevation of diastolic tension and depression of developed force. Although the injury response showed similarities between atrial and ventricular myocardium, there were significant differences as well. In rabbit atrial muscles, the development of the contracture and its peak was much faster as compared to ventricular muscles. Also, at the peak of contracture, both rabbit and dog atrial muscles show a lesser degree of contractile dysfunction. Conclusion:These results indicate that both atrial and ventricular muscles develop a rigor-like contracture after acute $\mathrm{OH}^{*}$-induced injury, and atrial muscles showed a lesser degree of contractile dysfunction. Comparison of dog versus rabbit tissue shows that the response was similar in magnitude, but slower to develop in dog tissue.

Keywords: calcium, heart, ischemia, peroxide, oxygen radicals, reperfusion, contractility

\section{INTRODUCTION}

Ischemic heart disease is one of the leading causes of death in developed countries. Timely and effective reperfusion is one of the treatment strategies for limiting the size of the infarct. However, despite optimal reperfusion therapy, there are many detrimental consequences of myocardial reperfusion. Reperfusion injury is a serious pathological process that is induced by the restoration of blood flow to previously ischemic tissue. When ischemic myocardium is reperfused, and oxygen reintroduced, there is a sudden burst of oxygen free radical production. Of these oxygen free radicals, the hydroxyl radical $\left(\mathrm{OH}^{\star}\right)$ is one of the most aggressive species, and is involved in the pathogenesis of ischemia-reperfusion injury (IR injury).IR injury is observed in many clinical situations including acute heart failure, stroke, and myocardial infarction (Gao et al., 1996; Zeitz et al., 2002). There is abundant information available regarding the ventricular myocardial response to $\mathrm{OH}^{*}$, but little is known about the contractile response of atrial myocardium to $\mathrm{OH}^{*}$-induced injury.

Previous studies by us and others have shown that intact contracting cardiac ventricular trabeculae from rat and rabbit after acute exposure of $\mathrm{OH}^{*}$ develop a rigor like contracture marked by an increase in diastolic tension, myofilament proteolysis, and overall decreased cardiac contractility (Zeitz et al., 2002; Hiranandani et al., 2006). Because it is well known that atrial tissue differs from ventricular tissue in morphological, electrophysiological, and also in pharmacological aspects, we conducted this study to compare the $\mathrm{OH}^{*}$-induced injury response between atrial and ventricular muscles. Previous studies have shown that there are differences in the small and large mammals in response to $\mathrm{OH}^{\star}$ (Zeitz et al., 2002). However, it is currently unknown if there are differences within large mammals in response to $\mathrm{OH}^{\star}$-induced injury. As rabbit and dog are similar to human regarding EC coupling (Janssen and Periasamy, 2007) and myofilament composition, we compared the $\mathrm{OH}^{\star}$ response between atrium and ventricle both in rabbit and dog under identical experimental conditions.

\section{MATERIALS AND METHODS PREPARATION OF RABBIT TRABECULAE AND OVERALL PROTOCOL}

Experiments were approved by The Ohio State University's Animal Care and Use Committee and comply with the laws of The United States of America as well as with the European Convention for the Protection of Vertebrate Animals used for Experimental and other Scientific Purposes. New Zealand White Rabbits $(2 \mathrm{~kg}$, approx 3 -months old) were anesthetized with $50 \mathrm{mg} / \mathrm{kg}$ pentobarbital sodium (IV) and injected with 5,000 units/kg heparin. The heart was rapidly removed and perfused retrogradely through the aorta with Krebs Henseleit solution containing (in mmol/L): $120 \mathrm{NaCl}, 5$ $\mathrm{KCl}, 2 \mathrm{MgSO}_{4}, 1.2 \mathrm{NaH}_{2} \mathrm{PO}_{4}, 20 \mathrm{NaHCO}_{3}, 0.25 \mathrm{Ca}^{2+}$ and 10 glucose ( $\mathrm{pH}$ 7.4) in equilibrium with $95 \% \mathrm{O}_{2} / 5 \% \mathrm{CO}_{2}$ at body temperature. Additionally, $20 \mathrm{mmol} / \mathrm{L}$ 2,3-butanedione monoxime (BDM) was added to the dissection solution to prevent damage during dissection (Mulieri et al., 1989, 1992; Janssen and Hunter, 1995). The effects of BDM after brief exposure have been found to be completely reversible (Mulieri et al., 1989; Janssen and Hunter, 1995). Suitable trabeculae were dissected carefully from the right atria and right ventricles without touching the central part of the muscle and mounted in the bath on top of the experimental setup (ter Keurs et al., 1980; de Tombe and ter Keurs, 1990; Janssen and de Tombe, 1997; Layland and Kentish, 1999; Janssen et al., 2002). The right ventricles and 
atria were chosen because the trabeculae found are generally more linear and appear in greater abundance, while myofilament properties and EC-coupling are nearly or completely identical to that of left ventricular trabeculae. Only thin muscles were used for the study, with a maximum diffusion distance of $100 \mu \mathrm{m}$ to the core, so core hypoxia will be avoided and not affect the outcome of the results (Raman et al., 2006). The trabeculae were connected to a hook-like extension of micromanipulator and the cube of wall tissue rested in a platinum-iridium basket-shaped extension of the force transducer. This method has been shown to minimize the end-damage compliance of the muscle and to prevent excessive loss of force throughout the experimental protocol (ter Keurs et al., 1980; de Tombe and ter Keurs, 1990; Janssen et al., 1999, 2002). The muscle was bathed in a continuous flow of oxygenated $\mathrm{K}-\mathrm{H}$ solution (without the BDM). Then muscle was stimulated at $2 \mathrm{~Hz}$ at a temperature of $37^{\circ} \mathrm{C}$, calcium concentration was raised to $1.5 \mathrm{mM}$ in the $\mathrm{K}-\mathrm{H}$ solution and stretched until maximal active force is reached. This length is comparable to maximally attained length in vivo at the end of diastole (around $2.2 \mu \mathrm{m}$ sarcomere length) (Rodriguez et al., 1992). After the stabilization of contractile parameters, we assessed the force frequency relationship by increasing the frequency from $2 \mathrm{~Hz}$ to $5 \mathrm{~Hz}$, then we exposed the muscle to $\mathrm{OH}^{*}$ for $2 \mathrm{~min}$. Twitch contractions were monitored until $45 \mathrm{~min}$ after $\mathrm{OH}^{\star}$ exposure. We repeated the force frequency protocol at this time of the injury response.

Twitch contractions are analyzed throughout the protocol, systolic and diastolic tension are recorded, and the difference was calculated to be developed tension. For twitch relaxation kinetics, time from peak tension to $50 \%$ and $90 \%$ were calculated.

\section{PREPARATION OF DOG TRABECULAE}

Myocardium from normal mongrel dogs (45 pounds approx, male/ female; 2-3 years of age) was obtained from normal control dogs (Billman et al., 2010), where the heart was freshly harvested, and we obtained a portion of the right ventricular free wall as well as the right atrium. From these tissues, suitable trabeculae were carefully dissected as previously described (Carnes et al., 2007; Billman et al., 2010). During the protocol, we used the exact same procedure as we did for rabbit trabeculae except the baseline frequency was set to $1 \mathrm{~Hz}$. Previous studies by us and others showed that rabbit and mouse trabeculae reached to a new steady state after $45 \mathrm{~min}$ of $\mathrm{OH}^{\star}$ induced injury (Janssen et al., 1999; Zeitz et al., 2002; Hiranandani et al., 2006). In this study, as we are comparing rabbit and dog atrial and ventricular trabeculae, we likewise measured the twitch contractions for $45 \mathrm{~min}$ after $\mathrm{OH}^{\star}$ exposure for $2 \mathrm{~min}$. We assessed the force frequency protocol by increasing the frequency from $1 \mathrm{~Hz}$ to $5 \mathrm{~Hz}$, then we exposed the muscle to $\mathrm{OH}^{\star}$ for $2 \mathrm{~min}$. Twitch contractions were monitored till $45 \mathrm{~min}$ after $\mathrm{OH}^{\star}$ exposure and thereafter repeated the force frequency protocol.

\section{HYDROXYL RADICAL EXPOSURE}

After the stabilization of contractile parameters, we exposed the muscle to $\mathrm{OH}^{\star}$ for $2 \mathrm{~min}$. Contractions were monitored until diastolic and developed force reached their new steady state (typically $45 \mathrm{~min}$ in our previous studies). In this study $\mathrm{OH}^{\star}$ was produced via the Fenton reaction through $\mathrm{H}_{2} \mathrm{O}_{2}+\mathrm{Fe}^{2+}-\mathrm{NTA}$ system (Zeitz et al., 2002):

$\mathrm{H}_{2} \mathrm{O}_{2}+\mathrm{Fe}^{2+} \rightarrow \mathrm{Fe}^{3+}+\mathrm{HO}^{-}+\mathrm{HO}^{\star}$
The reaction involves hydrogen peroxide and a ferrous iron as a catalyst. The hydrogen peroxide is broken down into a hydroxide ion and a hydroxyl free radical. The concentration of the $\mathrm{H}_{2} \mathrm{O}_{2}$ and Fe-NTA in the organ bath is $3.75 \mathrm{mM}$ and $10 \mu \mathrm{M}$ respectively. The amount of $\mathrm{OH}^{\star}$ generated under these conditions is comparable to those that occur in IR injury (Zweier et al., 1989; Zeitz et al., 2002). Pilot experiments and previous studies showed that using $\sim 3$ times lesser amounts of $\mathrm{OH}^{\star}$ does not elicit any injury, while $\sim 3$ times greater $\mathrm{OH}^{*}$ induces an non-recoverable injury response. $\mathrm{H}_{2} \mathrm{O}_{2}$ is infused via a separate line feed directly into the organ bath at the level of the muscle to ensure that radical formation took place directly in the muscle and muscle bath where $\mathrm{H}_{2} \mathrm{O}_{2}$ meets Fe-NTA. Controls, performed for this study, verified that either Fe-NTA alone, or $\mathrm{H}_{2} \mathrm{O}_{2}$ alone in the concentrations used did not have any effect on contractile parameters, and thus the assessed effects are results of products of the Fenton reaction specifically.

\section{DATA ANALYSIS AND STATISTICS}

Data were collected and analyzed on- and off-line using customwritten software in LabView (National Instruments). Data are expressed as means \pm SE unless otherwise stated. Data were statistically analyzed using ANOVA or Student's $t$-tests (paired or unpaired) where applicable. A two-tailed value of $p<0.05$ was considered significant.

\section{RESULTS}

After acute exposure of $\mathrm{OH}^{\star}$, intact cardiac trabeculae from atria and ventricles from dog and rabbit heart develop a rigor-like contracture marked by increase in diastolic and systolic tension and overall decreased contractility. This injury is initiated by $\mathrm{OH}^{*}$ radicals, as exposure to neither Fe-NTA alone, nor $\mathrm{H}_{2} \mathrm{O}_{2}$ alone exterted any effect on contractility. Since the $\mathrm{OH}^{\star}$ radical is very short lived, the contractile effects are not a direct result of $\mathrm{OH}^{\star}$ exposure, but of the cascade of events that follows $\mathrm{OH}^{\star}$ exposure. This cascade includes SR dysfunction and calcium overload (Zeitz et al., 2002), resulting in activation of calpain activation/caspases (Bolli and Marban, 1999) that have the ability to cleave proteins, such as myofilaments (Di Lisa et al., 1995; Gao et al., 1997), further leading to injury. In Figure 1 we show the contractile response of a muscle under baseline conditions followed by a 2 -min exposure with $\mathrm{OH}^{*}$ radicals in the atrial and ventricular cardiac trabeculae in rabbit and dog. In accordance with previous experiments using the same protocol, contractile parameters were the same before and after $\mathrm{OH}^{\star}$ exposure for all experiments (not shown). We measured these contractile parameters for $45 \mathrm{~min}$ after $\mathrm{OH}^{*}$ exposure. In rabbit trabeculae, after $45 \mathrm{~min}$, contractile parameters came to steady state, but in dog trabeculae contractile parameters had not (yet) come to steady state. 45 -min post $\mathrm{OH}^{\star}$ exposure was marked by an elevated diastolic tension, and depressed force development compared to the pre-interventional values in both rabbit and dog atrial and ventricular trabeculae.

Figure 2 shows the effect of acute $\mathrm{OH}^{*}$ exposure on diastolic and developed force. After the $\mathrm{OH}^{\star}$ there is an increase in diastolic force and decrease in developed force. The development of the contracture was much faster in atrial muscles compared to those 


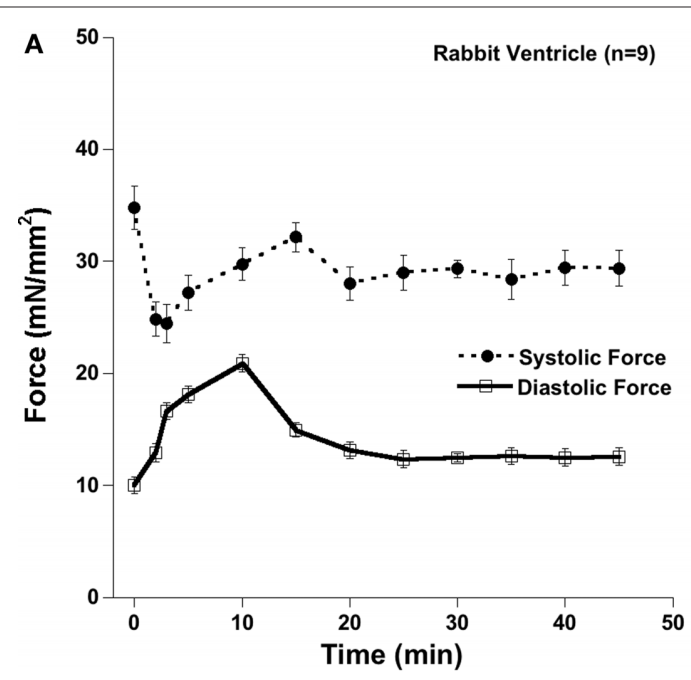

C

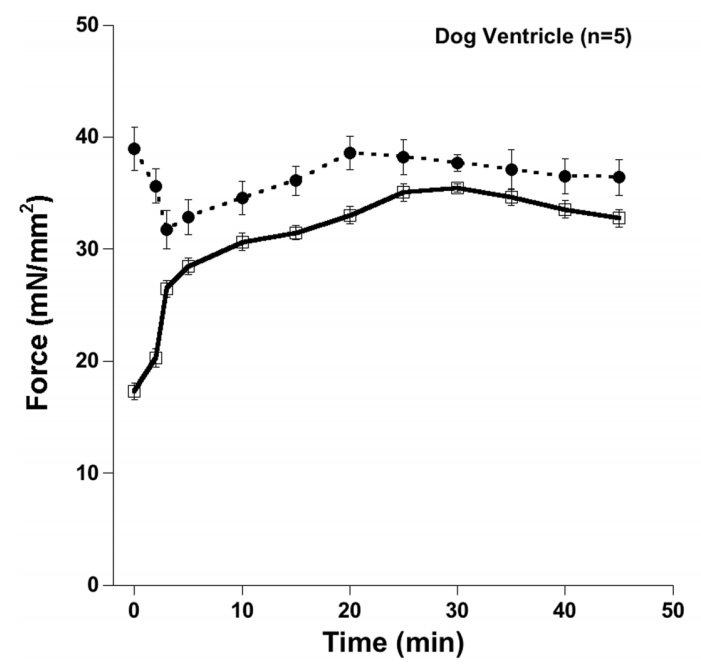

FIGURE 1 |Atrial and ventricular muscles from rabbit and dog developed a rigor like contracture after the exposure of $\mathbf{O H}^{*}$. After the acute $\mathrm{OH}^{*}$ exposure there is significant increase in diastolic force and systolic force. After $45 \mathrm{~min}$, there was still significant elevated diastolic and depressed

isolated from the ventricles. The amplitude of the contractures were also different in atrial and ventricular muscles; at the peak of contracture atrial muscles show less contractile dysfunction.

Figure 3 shows the same data (for easier comparison) expressed as the percentage effect of $\mathrm{OH}^{*}$ exposure on diastolic and developed force. In rabbit ventricular muscles diastolic force at the peak of contracture (at $\sim 12 \mathrm{~min}$ after $\mathrm{OH}^{\star}$ exposure) was increased to $240 \pm 7 \%(p<0.05)$ and developed force was decreased to $23 \pm 3 \%$ $(p<0.05)$ and partially recovered $125 \pm 8 \%(p<0.05)$ and $65 \pm 4 \%$ $(p<0.05)$ respectively. In rabbit atrial muscles at the peak of contracture (occurring at $\sim 7$-min post exposure) developed force was decreased to $19 \pm 2 \%(p<0.05)$ while diastolic force was increased to $217 \pm 20 \%(p<0.05)$, and thereafter recover at the 45 -min mark to $38 \pm 8 \%(p<0.05)$ and $141 \pm 11 \%(p<0.05)$ respectively.

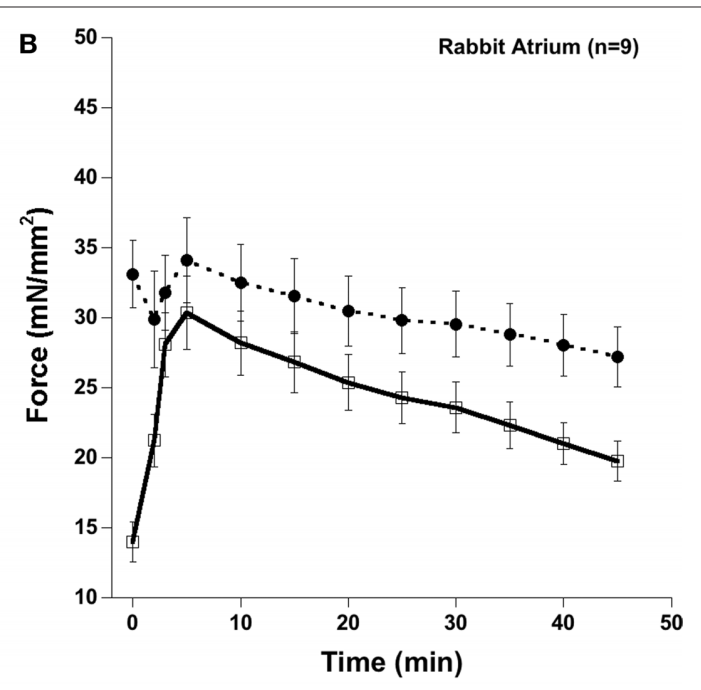

D

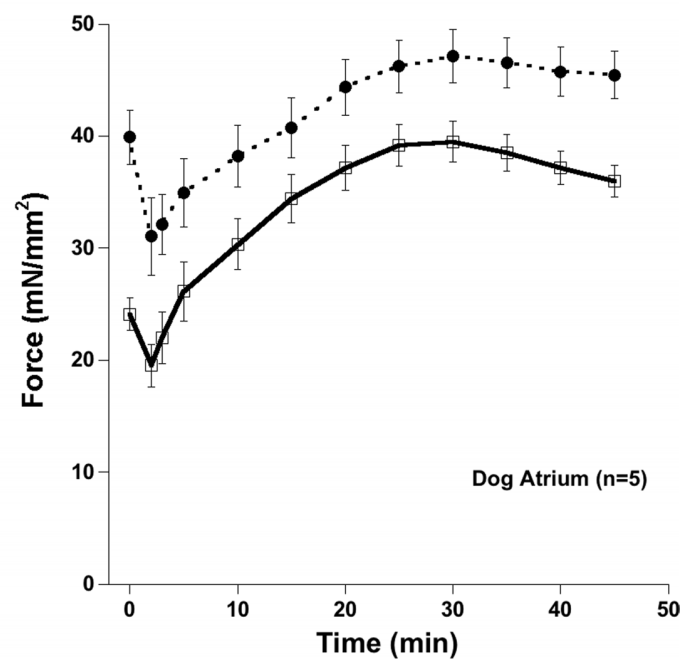

systolic force. Baseline stimulation frequency was $2 \mathrm{~Hz}$ in rabbit and $1 \mathrm{~Hz}$ in dog and temperature was $37^{\circ} \mathrm{C}$ throughout the experiment. (A) Rabbit Ventricle, (B) Rabbit Atrium, (C) Dog Ventricle, (D) Dog Atrium.

In dog myocardium, the peak of $\mathrm{OH}^{\star}$-induced injury contracture occurred much later than in rabbit muscles. In dog ventricular muscles, diastolic force at the peak of contracture (occurring $\sim 25 \mathrm{~min}$ after $\mathrm{OH}^{*}$ exposure) was increased to $202 \pm 33 \%(p<0.05)$ and developed force was decreased to $16 \pm 3 \%(p<0.05)$ and recovered to $188 \pm 40 \%(p<0.05)$ and $17 \pm 3 \%(p<0.05)$ respectively at the 45 -min mark. In dog atrial muscles at the peak of contracture (at $\sim 25 \mathrm{~min}$ ), developed force was decreased to $50 \% \pm 7(p<0.05)$ while was diastolic force was increased to $159 \pm 27 \%(p<0.05)$, and recovered to $59 \pm 8 \%(p<0.05)$ and $149 \pm 23 \%(p<0.05)$ respectively after $45 \mathrm{~min}$ of $2 \mathrm{~min} \mathrm{OH}^{*}$ exposure. This shows that the sustained contractile dysfunction was much higher in atrial muscles as compared to ventricular muscles in both species used. The 


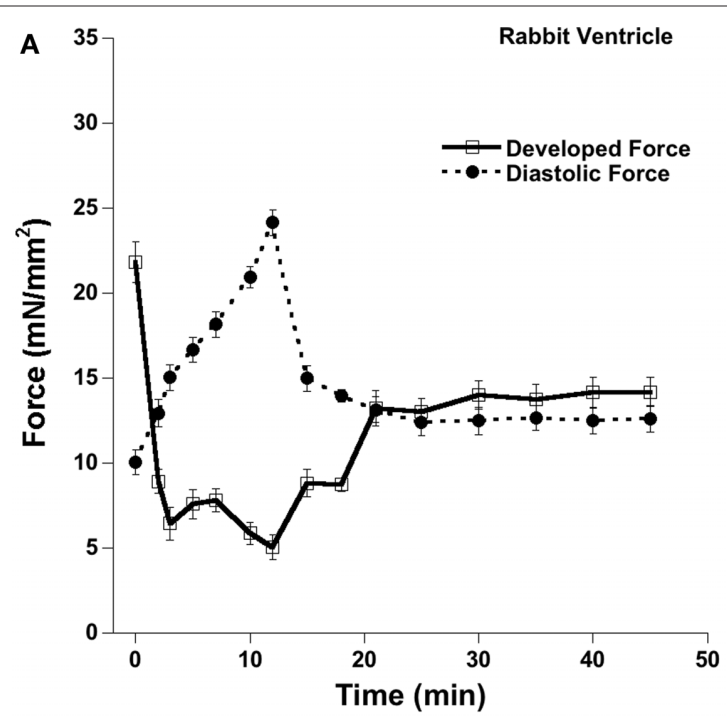

c

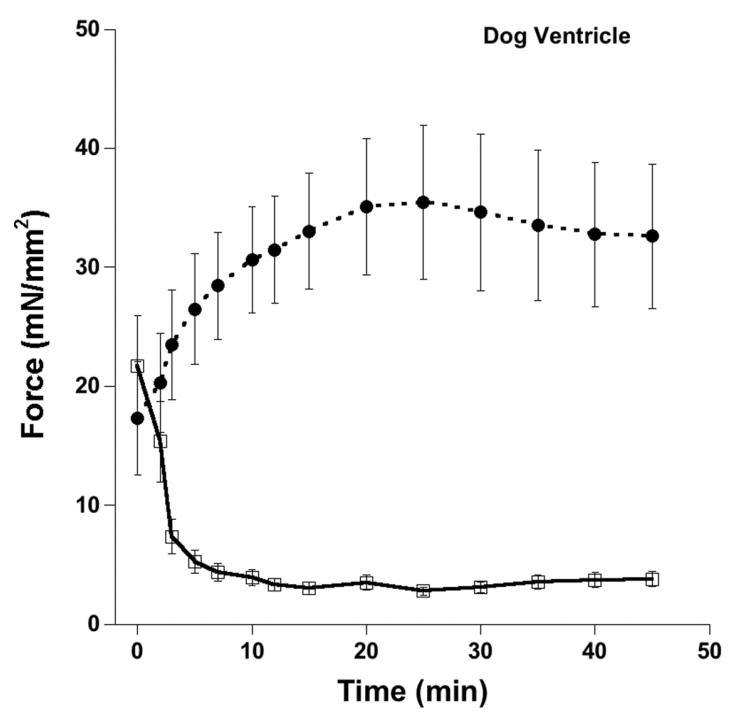

FIGURE 2 | Effect of 2-min exposure of $\mathrm{OH}$-radicals on the contractile parameters of the cardiac trabeculae. At peak of contracture there is a significant increase in diastolic force and a significant decrease in developed force. After 45 min, parameters started to level off, and this state was marked by

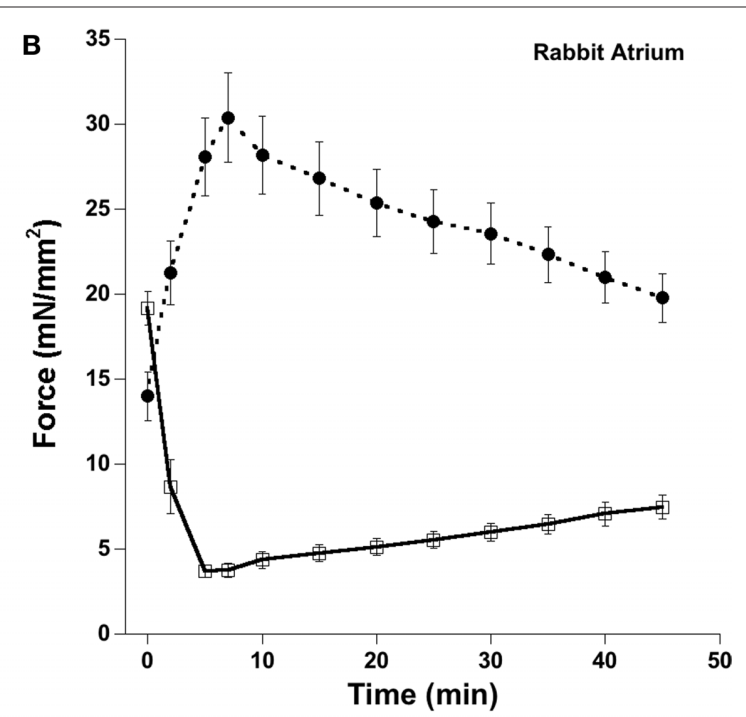

D

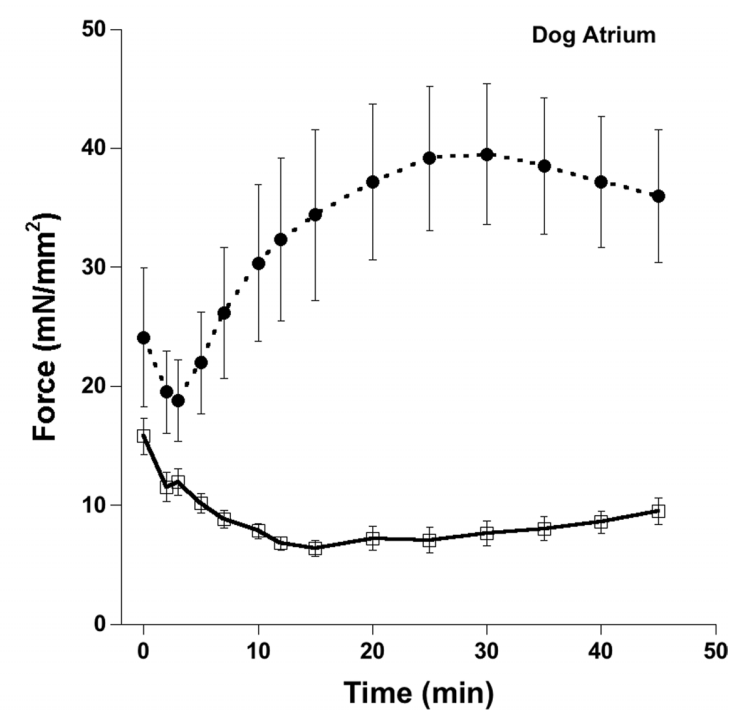

significant elevated diastolic force and reduced developed force. Stimulation frequency $2 \mathrm{~Hz}$ in rabbit and $1 \mathrm{~Hz}$ in dog and temperature was $37^{\circ} \mathrm{C}$ throughout the experiment. (A) Rabbit Ventricle, (B) Rabbit Atrium, (C) Dog Ventricle, (D) Dog Atrium. sustained dysfunction was also much greater in dog trabeculae as compared to rabbit because dog trabeculae did not come to a steady state yet after $45 \mathrm{~min}$ as the frequency of stimulation in dog muscles was half than the rabbit trabeculae.

The observation of elevated diastolic force and reduced developed force at the 45-min mark was accompanied by a slower relaxation (Figure 4). Both RT50\% and RT90\% were significantly slower in atrial and ventricular muscles in both rabbit and dog after $\mathrm{OH}^{\star}$-induced injury compared to before injury. Compared to RT50\%, RT90\% was much slower in ventricular muscles as compared to atrial muscles, possibly indicating a specific impairment of relaxation kinetics in the later part of relaxation. There was no significant difference in time to peak and the first derivative of force $(\mathrm{dF} / \mathrm{dt})$ between atrial and ventricular muscles.

Figure 5 shows the force-frequency relationship before and after $\mathrm{OH}^{*}$-induced injury in atrial and ventricular muscles. An increase in stimulation frequency from 2 to $5 \mathrm{~Hz}$ in rabbit and 1 to $5 \mathrm{~Hz}$ in dog cardiac trabeculae shows a typical (Varian and Janssen, 2007) increase in developed force before $\mathrm{OH}^{\star}$ but a flat or negative force frequency was obtained after the $\mathrm{OH}^{\star}$-induced injury. As the deviation of force frequency is a characterization of SR function, this change from a positive to a flat/negative after 


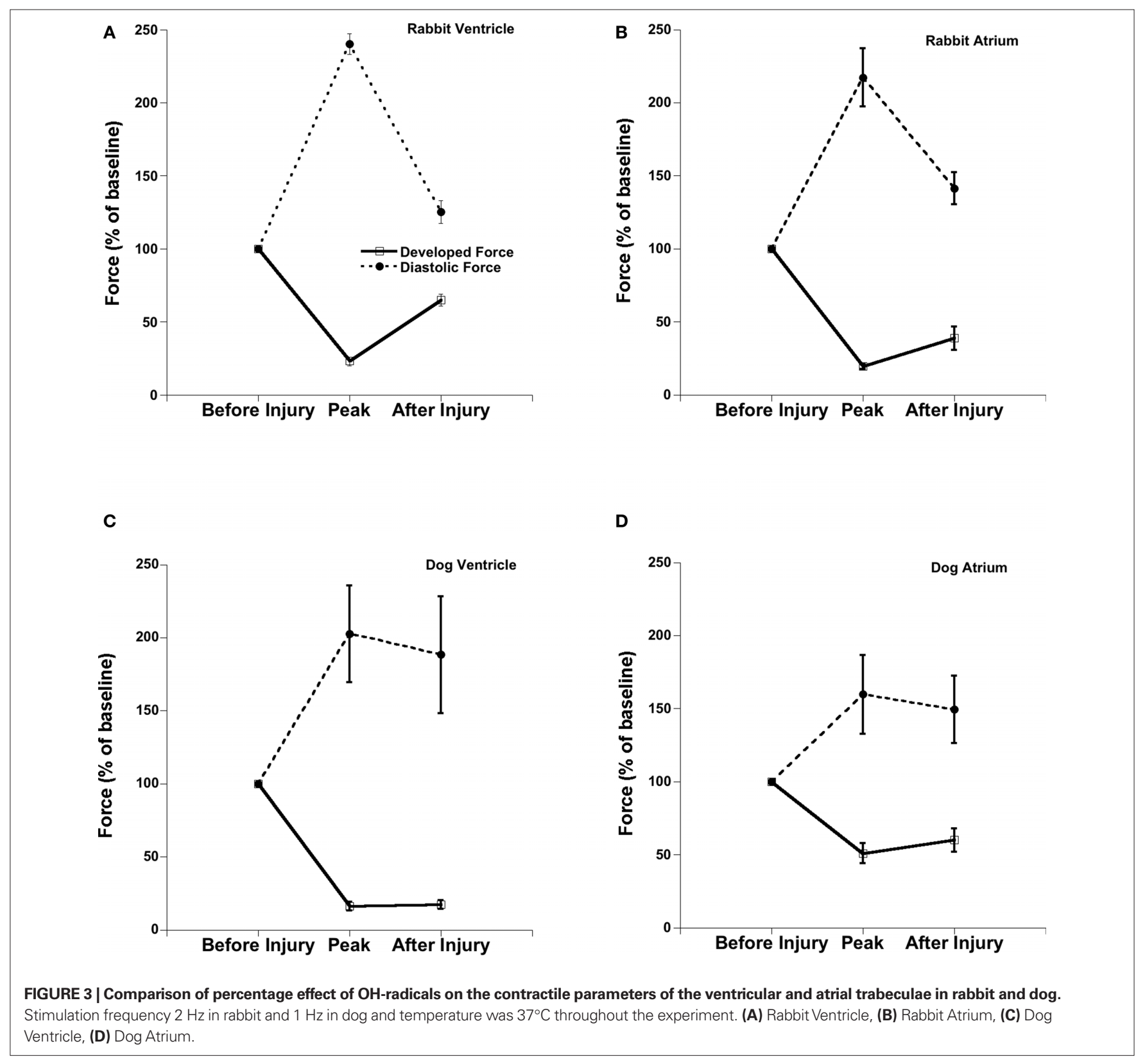

$\mathrm{OH}^{\star}$ exposure indicates an impairment of SR function, which is one of the hallmarks of congestive heart failure (Rossman et al., 2004) and/or hypertrophy (Varian et al., 2009).

\section{DISCUSSION}

The results of this study show that direct acute exposure of $\mathrm{OH}^{\star}$ to clinically relevant levels of reperfusion injury leads to a transient rigor like contracture in both atrial and ventricular myocardium. During the acute phase there is a marked increase in diastolic force in parallel with decrease in developed force. During the recovery phase, diastolic force declines and developed force increases somewhat, but these parameters do not nearly recover to the pre- $\mathrm{OH}^{*}$ levels. Although this result is similar to what has been previously described in ventricular muscles (Zeitz et al., 2002; Hiranandani et al., 2006), we did also observe significant differences between atrial and ventricular tissue in their response to $\mathrm{OH}^{\star}$-induced injury. In rabbit atrial muscles, the development of the injury contracture occurred much faster compared to the response in ventricular muscles. Despite a more rapid onset, at the peak of contracture rabbit atrial muscles show less contractile dysfunction when compared to ventricular muscles in the same species. Assessment of RT90\% indicated that relaxation kinetics were significantly prolonged after $\mathrm{OH}^{*}$-induced injury, as well as and much faster in atrial muscles compared to ventricular ones. This prolongation of the twitch force might be due to a calcium reabsorption delay by the sarcoplasmic reticulum. It is known that with the increasing concentration of $\mathrm{OH}^{*}$ there is a decrease in SERCA activity (Flesch et al., 1999). This decrease in SERCA activity leads to slower re-sequestration of calcium in SR resulting in slower initiation of relaxation after $\mathrm{OH}^{*}$ injury. The depressed contractile function was also accompanied by 


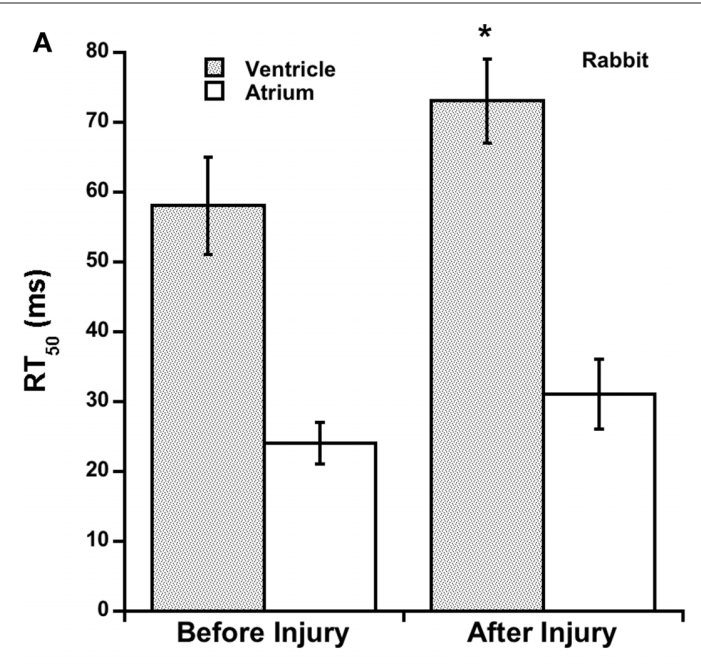

C

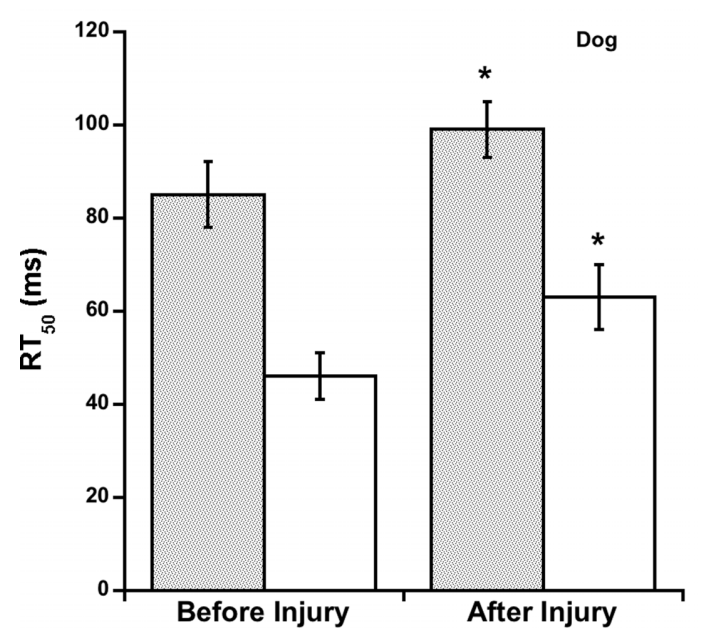

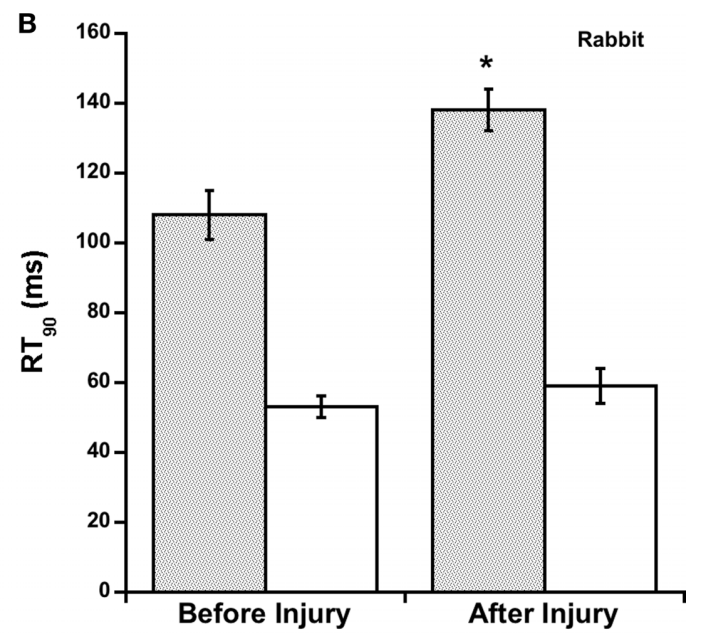

D

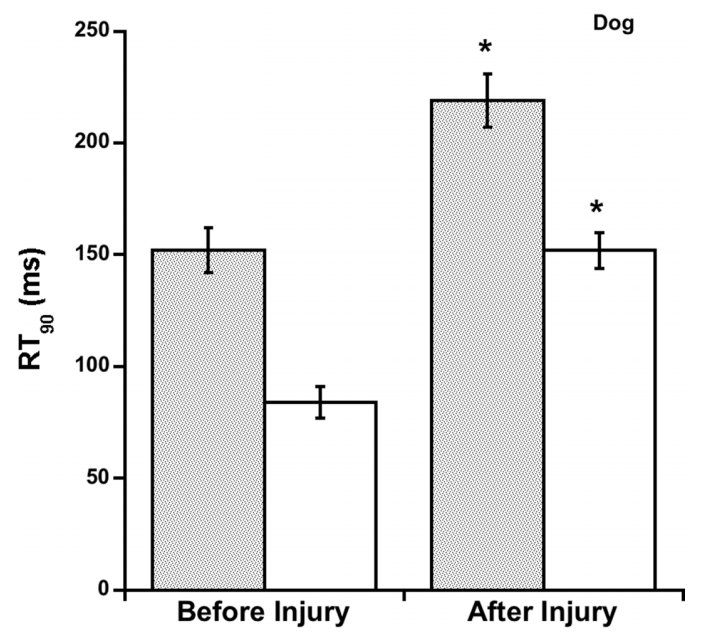

FIGURE 4 | Time from peak tension to $\mathbf{5 0} \%$ relaxation (RT50\%) and time from peak tension to $\mathbf{9 0} \%$ relaxation (RT90\%), before and after $\mathrm{OH}$-induced injury are significantly different in rabbit ventricular trabeculae, and in dog ventricular and atrial trabeculae. ${ }^{*}$ indicates a difference of $p<0.05$ between conditions in the same group. (A) Rabbit, RT50, (B) Rabbit RT90, (C) Dog, RT50, (D) Dog, RT90.

a flat/negative force frequency response, one of the classic hallmarks of heart failure (Ferrari et al., 1993; Janssen et al., 1999; Zeitz et al., 2002; Rossman et al., 2004), after the $\mathrm{OH}^{*}$-induced injury. These results indicate that both atrial and ventricular muscles develop a rigor like contracture after acute $\mathrm{OH}^{*}$-induced injury but in atrial muscles the contractile dysfunction is less severe in magnitude in both species, and in rabbit atrial muscles reached its maximum effect faster then in ventricular muscles.

It has long been known that the action potential in atrial muscles is much shorter in comparison to ventricular muscles, along with faster rate of contraction and relaxation of the myofilaments (Korecky and Michael, 1974; Asgrimsson et al., 1995). Despite different relaxation kinetics, calcium sensitivity and tension kinetics were same in atrial and ventricular muscles (Vannier et al., 1996). These studies indicate that these atrioventricular differences in relaxation kinetics are mainly due to the different SR calcium handling ability of atrial tissue. It is also known that there is a decrease in SERCA activity with increasing concentration of $\mathrm{OH}^{\star}$ (Flesch et al., 1999) as well as clear attenuation of force-frequency response after $\mathrm{OH}^{\star}$ exposure (Schouten and ter Keurs, 1986; Janssen et al., 1999). These studies likewise indicate that direct impairment of SR function and calcium overload plays a significant role in acute cardiac dysfunction due to reperfusion injury.

Atrial muscles also have a lower phospholamban to SERCA ratio which leads to faster SR calcium uptake resulting in faster cessation of contraction and initiation of relaxation in atrial compared to ventricular tissue (Koss et al., 1995). In accordance with these studies our data also showed that after acute $\mathrm{OH}^{\star}$ exposure at clinically relevant levels, atrial muscles develop a transient rigor-like contracture similar to ventricular muscles, but with a less severe amplitude. We previously 

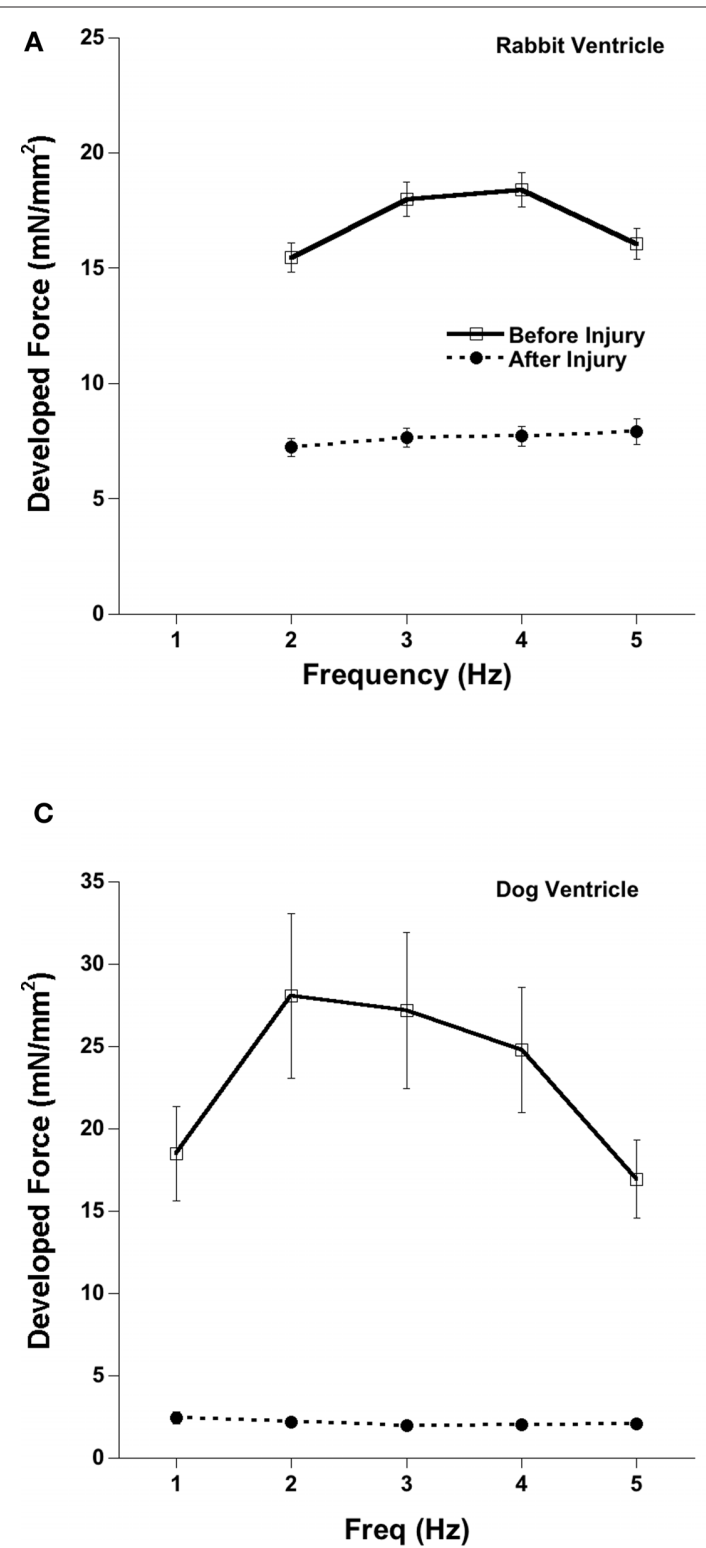

FIGURE 5 | Force-Frequency relationships before and after $\mathbf{2}$ min of OH-radical exposure on cardiac trabeculae. About 45-60 min after

$\mathrm{OH}$-exposure, the flat force-frequency relationship was much less pronounced

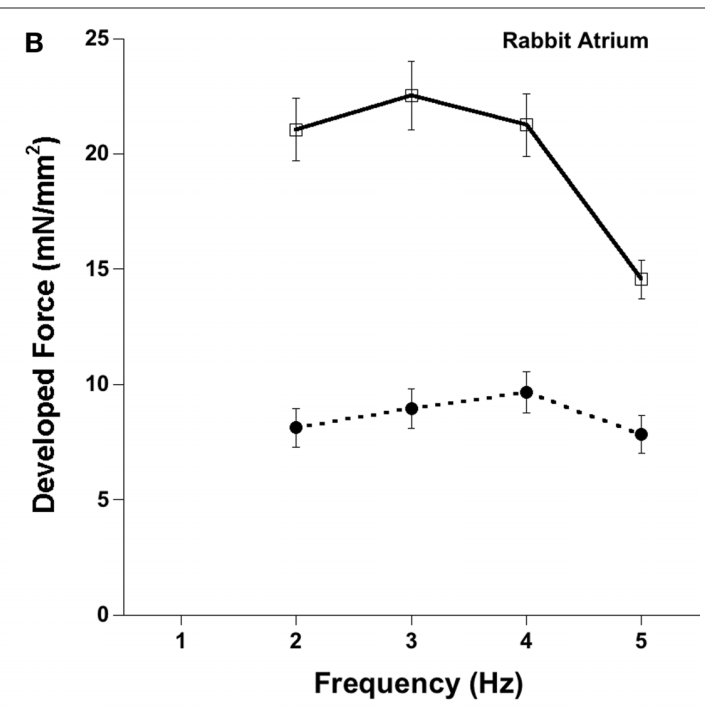

D

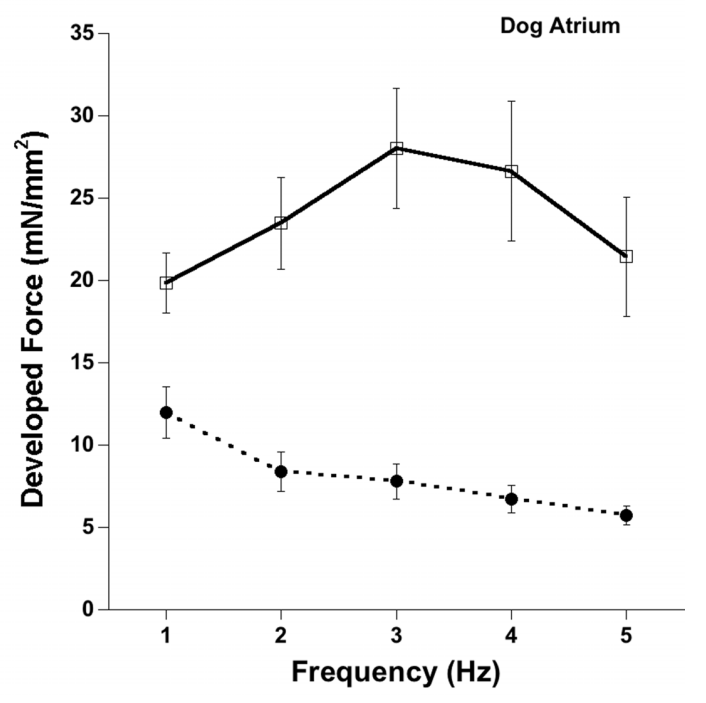

compared to the positive force-frequency relationship assessed before application of $\mathrm{OH}$-radicals in both atrial and ventricular trabeculae in rabbit and dog. (A) Rabbit Ventricle, (B) Rabbit Atrium, (C) Dog Ventricle, (D) Dog Atrium showed that SERCA over-expression, in ventricular tissue, can reduce the $\mathrm{OH}^{*}$-induced contractile dysfunction in murine myocardium, whereas a reduced SR $\mathrm{Ca}^{2+}$ ATPase activity aggravates this injury (Hiranandani et al., 2006). The higher expression of SERCA 2a in atria as compared to ventricular muscles (Minajeva et al., 1997), is thus likely responsible for our findings that at the peak of contracture atrial muscles show less contractile dysfunction.

Pressures developed by the atrial contraction are much less then the ventricular pressures. Thus, a similar absolute reduction in pressure development by both atria and ventricles will dominantly affect ventricular function. We show here that although atrial muscles too suffer from a loss of force development, this is of a lesser magnitude the ventricular loss of force. Still, if the ventricular force development is impaired, or relaxation kinetics slowed, the atrial contraction needs to overcome a greater pressure gradient, and thus loss of force may become clinically relevant. For instance, if the rabbit heart hypertrophies such that the relaxation kinetics are significantly slowed, atrial hypertrophy occurs to compensate for the higher workload as shown recently (Gupta et al., 2009). Thus, loss of force due to $\mathrm{OH}$-radicals, specifically in already hypertrophied myocardium, may thus have a significant impact on atrial function. In addition to the impact on contractile function, $\mathrm{OH}$-radical induced dysfunction is mediated via calcium overload, which could have profound implications for electrical stability of atrial pacemaker cell activity, and thus could also potentially be clinically relevant for cardiac arrhythmic behavior. 
In dog muscles the development of the contracture was significantly slower and sustained function was higher as compared to the response in rabbit muscles. Twitch contractions are dependent on the baseline frequency and the baseline frequency for dog is nearly half as that of the rabbit, and thus this may partially responsible for the difference. However, the atrial and ventricular muscles per species were contracting at the same rate, thus rate does not, or at least not alone, dictate the level of response. In this study, as we compared rabbit and dog atrial and ventricular trabeculae, we measured the twitch contractions for $45 \mathrm{~min}$ after $\mathrm{OH}^{\star}$ exposure at $1 \mathrm{~Hz}$ in dog and $2 \mathrm{~Hz}$ in rabbit. After $45 \mathrm{~min}$, contractile parameters came to a new steady state in rabbit ventricular trabeculae, as well as in some but not all rabbit atrial muscles. In contrast, none of the measured dog trabeculae contractile parameters had come to steady state at 45-min past exposure. This may be the possible reason for late peak of contracture and higher sustained dysfunction in dog after $45 \mathrm{~min}$ as compared to rabbit. A pilot experiment in a singe dog ventricular muscle assessed for $90 \mathrm{~min}$ showed that the contracture did reach a new steady state after $\sim 75 \mathrm{~min}$.

In a previous study we showed that in absence of SR function the positive force-frequency relationship is maintained in large mammal (rabbit) as compared to small mammal (rat) where it becomes negative (Monasky and Janssen, 2009). In this study we looked at the force frequency response between rabbit and dog before and after $\mathrm{OH}^{*}$ injury to find if an $\mathrm{OH}$-radical induced decrease in SR function can still maintain the positive force frequency response in large mammals. Our results showed that after $\mathrm{OH}^{\star}$ induced injury depressed contractile function was also accompanied by negative

\section{REFERENCES}

Asgrimsson, H., Johannsson, M., and Arnardottir, S. A. (1995). Excitation and contraction in atrial and ventricular myocardium of the guinea-pig. Acta Physiol. Scand. 153, 133-141.

Billman, G. E., Nishijima, Y., Belevych, A. E., Terentyev, D., Xu, Y., Haizlip, K. M., Monasky, M. M., Hiranandani, N., Harris, W. S., Gyorke, S., Carnes, C.A., and Janssen, P. M. (2010). Effects of dietary omega-3 fatty acids on ventricular function in dogs with healed myocardial infarctions: in vivo and in vitro studies. Am. J. Physiol. Heart Circ. Physiol. 298, H1219-H1228.

Bolli, R., and Marban, E. (1999). Molecular and cellular mechanisms of myocardial stunning. Physiol. Rev. 79, 609-634.

Carnes, C. A., Janssen, P. M., Ruehr, M. L., Nakayama, H., Nakayama, T., Haase, H., Bauer, J. A., Chung, M. K., Fearon, I. M., Gillinov, A. M., Hamlin, R. L., and Van Wagoner, D. R. (2007). Atrial glutathione content, calcium current, and contractility. J. Biol. Chem. 282, 28063-28073.

de Tombe, P.P., and ter Keurs, H.E. (1990). Force and velocity of sarcomere shortening in trabeculae from rat heart. Effects of temperature. Circ. Res. 66, 1239-1254.
Di Lisa, F., De Tullio, R., Salamino, F., Barbato, R., Melloni, E., Siliprandi, N., Schiaffino, S., Pontremoli, S., and Bolli, R. (1995). Specific degradation of troponin $\mathrm{T}$ and $\mathrm{I}$ by mu-calpain and its modulation by substrate phosphorylation. Biochem. J. 308, 57-61. applicable interventions designed to prevent postischemic ventricular dysfunction.

Ferrari, R., Curello, S., Ceconi, C., Cargnoni, A., Pasini, E., and Visioli, O. (1993). Cardioprotection by nisoldipine: role of timing of administration. Eur. Heart J. 14, 1258-1272.

Flesch,M., Maack, C., Cremers, B., Baumer, A. T., Sudkamp, M., and Bohm, M. (1999). Effect of beta-blockers on free radical-induced cardiac contractile dysfunction. Circulation 100, 346-353.

Gao, W. D., Atar, D., Liu, Y., Perez, N. G., Murphy, A. M., and Marban, E. (1997). Role of troponin I proteolysis in the pathogenesis of stunned myocardium. Circ. Res. 80, 393-399.

Gao, W. D., Liu, Y., and Marban, E. (1996). Selective effects of oxygen free radicals on excitation-contraction coupling in ventricular muscle. Implications for the mechanism of stunned myocardium. Circulation 94, 2597-2604.

force frequency response in dog, but in rabbit a positive response was somewhat maintained. This again could (at least in part) be due to baseline frequency we used for dog and rabbit. A limitation of this study includes that, although a direct assessment of SR function including intracellular calibrated calcium transients is now possible in rabbit (Monasky and Janssen, 2009), in dog myocardium the same approach has yet to be developed, and at present we thus do not have a direct confirmation of depressed SR function in the dog, or in atrial versus ventricular muscle. Future studies could be undertaken to study whether therapies directed primarily against ventricular I/R injury are likewise effective, or perhaps more effective given the less severe injury, in atrial tissue. Upregulation of SERCA function, via virus-mediated expression (Miyamoto et al., 2000), or anti-oxidant therapy, such as NAC ( $N$-acetyl $L$-cysteine) and MPG (N-(2-mercaptopropionyl)-glycine) (Saini-Chohan and Dhalla, 2009) may provide therapeutic avenues for atrial I/R injury.

In conclusion, we show that direct acute exposure of $\mathrm{OH}^{\star}$ to clinically relevant levels of reperfusion injury leads to transient rigor like contracture marked by an increase in diastolic contraction and overall decrease contractility with partial recovery in both atrial and ventricular muscles from the rabbit and dog.

\section{ACKNOWLEDGMENTS}

This work was supported by National Heart, Lung, and Blood Institute grants R01 [HL-738616 to Paul M.L.Janssen]; an established investigator award of the American Heart Association [0740040N to Paul M. L. Janssen]; and an American Heart Association predoctoral grant [0715127B to Nitisha Hiranandani].

Gupta, S. C., Varian, K. D., Bal, N. C., Abraham, J. L., Periasamy, M., and Janssen, P. M. L. (2009). Pulmonary artery banding alters the expression of $\mathrm{Ca} 2+$ transport proteins in the right atrium in rabbits. Am. J. Physiol. Heart Circ. Physiol. 296, H1933-H1939.

Hiranandani, N., Bupha-Intr, T., and Janssen, P. M. L. (2006). SERCA overexpression reduces hydroxyl radical injury in murine myocardium. Am. J. Physiol. Heart Circ. Physiol. 291, H3130-H3135.

Janssen, P. M., and Periasamy, M. (2007). Determinants of frequency-dependent contraction and relaxation of mammalian myocardium. J. Mol. Cell. Cardiol. 43, 523-531.

Janssen, P.M.L., and de Tombe, P.P.(1997). Uncontrolled sarcomere shortening increases intracellular Ca2+ transient in rat cardiac trabeculae. Am. J. Physiol. 272, H1892-H1897.

Janssen, P. M. L., and Hunter, W. C. (1995). Force, not sarcomere length, correlates with prolongation of isosarcometric contraction. Am. J. Physiol. Heart Circ. Physiol. 269, H676-H685.

Janssen, P. M. L., Stull, L. B., and Marban, E. (2002). Myofilament properties comprise the rate-limiting step for cardiac relaxation at body temperature in the rat. Am. J. Physiol. Heart Circ. Physiol. 282, H499-H507.

Janssen, P. M. L., Zeitz, O., and Hasenfuss, G. (1999). Transient and sustained impacts of hydroxyl radicals on sarcoplasmic reticulum function: protective effects of nebivolol. Eur. J. Pharmacol. 366, 223-232.

Korecky, B., and Michael, L. H. (1974). Regional differences in contractions of mammalian hearts. Recent Adv. Stud. Cardiac Struct. Metab. 4, 77-87.

Koss, K. L., Ponniah, S., Jones, W. K., Grupp, I. L., and Kranias, E. G. (1995). Differential phospholamban gene expression in murine cardiac compartments. Molecular and physiological analyses. Circ. Res. 77, 342-353.

Layland, J., and Kentish, J. C. (1999). Positive force- and [Ca2+]i-frequency relationships in rat ventricular trabeculae at physiological frequencies. Am J. Physiol. Heart Circ. Physiol. 276, H9-H18.

Minajeva, A., Kaasik, A., Paju, K., Seppet, E., Lompre, A. M., Veksler, V., and Ventura-Clapier, R. (1997). Sarcoplasmic reticulum function in determining atrioventricular contractile differences in rat heart. Am. J. Physiol. 273, H2498-H2507.

Miyamoto, M. I., del Monte, F., Schmidt, U., DiSalvo, T. S., Kang, Z. B., Matsui, 
T., Guerrero, J. L., Gwathmey, J. K., Rosenzweig, A., and Hajjar, R. J. (2000). Adenoviral gene transfer of SERCA2a improves left-ventricular function in aortic-banded rats in transition to heart failure. Proc. Natl. Acad. Sci. U.S.A. 97, 793-798.

Monasky, M. M., and Janssen, P. M. L. (2009). The positive force-frequency relationship is maintained in absence of sarcoplasmic reticulum function in rabbit, but not in rat myocardium. J. Comp. Physiol. B. 179, 469-479.

Mulieri, L. A., Hasenfuss, G., Ittleman, F., Blanchard, E. M., and Alpert, N. R. (1989). Protection of human left ventricular myocardium from cutting injury with 2,3-butanedione monoxime. Circ. Res. 65, 1441-1449.

Mulieri, L. A., Hasenfuss, G., Leavitt, B., Allen, P. D., and Alpert, N. R. (1992). Altered myocardial force-frequency relation in human heart failure. Circulation 85, 1743-1750.

Raman, S., Kelley, M.A., and Janssen, P.M. (2006). Effect of muscle dimensions on trabecular contractile performance under physiological conditions. Pflugers Arch. 451, 625-630.

Rodriguez, E. K., Hunter, W. C., Royce, M. J., Leppo, M. K., Douglas, A. S., and Weisman, H. F. (1992). A method to reconstruct myocardial sarcomere lengths and orientations at transmural sites in beating canine hearts. Am. J. Physiol. 263, H293-H306.

Rossman, E. I., Petre, R. E., Chaudhary, K. W., Piacentino, V., 3rd, Janssen, P. M., Gaughan, J. P., Houser, S. R., and Margulies, K. B. (2004). Abnormal frequency-dependent responses represent the pathophysiologic signature of contractile failure in human myocardium. J. Mol. Cell. Cardiol. 36, 33-42.

Saini-Chohan, H. K., and Dhalla, N. S. (2009). Attenuation of ischemia-reperfusion-induced alterations in intracellular $\mathrm{Ca} 2+$ in cardiomyocytes from hearts treated with $\mathrm{N}$-acetylcysteine and N-mercaptopropionylglycine. Can. J. Physiol. Pharmacol. 87, 1110-1119.

Schouten, V.J., and ter Keurs, H.E. (1986). The force-frequency relationship in rat myocardium. The influence of muscle dimensions. Pflugers Arch. 407, 14-17.

ter Keurs, H. E., Rijnsburger, W. H., van Heuningen, R., and Nagelsmit, M. J. (1980). Tension development and sarcomere length in rat cardiac trabeculae. Evidence of length-dependent activation. Circ. Res. 46, 703-714.
Vannier, C., Chevassus, H., and Vassort, G. (1996). Ca-dependence of isometric force kinetics in single skinned ventricular cardiomyocytes from rats. Cardiovasc. Res. 32, 580-586.

Varian, K. D., and Janssen, P. M. (2007) Frequency-dependent acceleration of relaxation involves decreased myofilament calcium sensitivity. Am. J. Physiol. Heart Circ. Physiol. 292, H2212-H2219.

Varian, K. D., Kijtawornrat, A., Gupta, S. C., Torres, C. A., Monasky, M. M., Hiranandani, N., Delfin, D. A., RafaelFortney, J. A., Periasamy, M., Hamlin, R. L., and Janssen, P. M. (2009). Impairment of diastolic function by lack of frequency-dependent myofilament desensitization rabbit right ventricular hypertrophy. Circ Heart Fail 2, 472-481.

Zeitz, O., Maass, A. E., Van Nguyen, P., Hensmann, G., Kogler, H., Moller, K., Hasenfuss, G., and Janssen, P. M. L. (2002). Hydroxyl radical-induced acute diastolic dysfunction is due to calcium overload via reverse-mode $\mathrm{Na}(+)-\mathrm{Ca}(2+)$ exchange. Circ. Res. 90, 988-995.

Zweier, J. L., Kuppusamy, P., Williams, R., Rayburn, B. K., Smith, D., Weisfeldt, M. L., and Flaherty, J. T. (1989).
Measurement and characterization of postischemic free radical generation in the isolated perfused heart. J. Biol. Chem. 264, 18890-18895.

Conflict of Interest Statement: The authors declare that the research was conducted in the absence of any commercial or financial relationships that could be construed as a potential conflict of interest.

Received: 03 June 2010; paperpending published: 01 July 2010; accepted: 22 July 2010; published online: 30 September 2010.

Citation: Hiranandani N, Billman GE and Janssen PML (2010) Effects of hydroxyl radical induced-injury in atrial versus ventricular myocardium of dog and rabbit. Front. Physio. 1:25. doi: 10.3389/ fphys.2010.00025

This article was submitted to Frontiers in Oxidant Physiology, a specialty of Frontiers in Physiology.

Copyright (C) 2010 Hiranandani, Billman and Janssen. This is an open-access article subject to an exclusive license agreement between the authors and the Frontiers Research Foundation, which permits unrestricted use, distribution, and reproduction in any medium, provided the original authors and source are credited. 